\title{
Laboratory evaluation of falling-head infiltration for saturated soil hydraulic conductivity determination
}

\author{
Paola Concialdi, ${ }^{1}$ Vincenzo Bagarello, ${ }^{1}$ Vincenzo Alagna, ${ }^{2}$ Massimo Iovino ${ }^{1}$ \\ ${ }^{1}$ Dipartimento di Scienze Agrarie, Alimentari e Forestali, Università di Palermo; ${ }^{2}$ Dipartimento di Scienze e Tecnologie \\ Agro-Alimentari, Alma Mater Studiorum Università di Bologna, Italy
}

\begin{abstract}
Falling-head one-dimensional infiltration procedures, such as the simplified falling-head (SFH) technique, yield estimates of saturated soil hydraulic conductivity, $K_{s}$, with parsimonious and rapid experiments. Factors that can influence determination of $K_{S}$ by the SFH technique were tested in the laboratory on three repacked soils differing by particle diameter ranges (0-2000, 0105 and 105-2000 $\mu \mathrm{m}$, respectively). Using the theoretically calculated depth of ponding on the infiltration surface, $D$, instead of the measured one had a small impact on the $K_{S}$ calculations (means differing by a factor of 1.1-1.2, depending on the soil). For the finest soil, $K_{S}$ decreased by 3.1 times as $D$ increased from 40 to $135 \mathrm{~mm}$ but $D$ did not affect $K_{S}$ for the coarsest soil, yielding in general the highest $K_{S}$ values. The abrupt increase of the infiltration rate close to the end of the run did not influence appreciably $K_{S}$ calculations since it determined an increase in $K_{S}$ by a mean factor never exceeding 1.1. The most frequent result of the developed procedure for estimating the $\alpha^{*}$ parameter was failure of the experiment although the valid $\alpha^{*}$ calculations were plausible, being higher for the coarse textured soil $\left(17 \mathrm{~m}^{-1}\right)$ than the finer soils $\left(9.2-9.3 \mathrm{~m}^{-1}\right)$. The depth of the wetting front at the end of the run was 1.1-1.2 times deeper than that calculated theoretically before the run, depending on the soil. In conclusion, the method used to determine $D$ should not affect very much $K_{S}$ determination but larger $D$ values can yield smaller $K_{S}$ values in fine-textured soils. Air escapes from the sampled soil volume when almost all
\end{abstract}

Correspondence: Vincenzo Bagarello, Dipartimento di Scienze Agrarie, Alimentari e Forestali, Università di Palermo, Viale delle Scienze, Edificio 4, 90128 Palermo, Italia.

E-mail: vincenzo.bagarello@unipa.it

Key words: Laboratory investigation; saturated soil hydraulic conductivity; falling-head one-dimensional infiltration; simplified falling-head technique.

Received for publication: 26 July 2019.

Accepted for publication: 25 September 2019.

C Copyright: the Author(s), 2019

Licensee PAGEPress, Italy

Journal of Agricultural Engineering 2020; LI:1003

doi:10.4081/jae.2019.1003

This article is distributed under the terms of the Creative Commons Attribution Noncommercial License (by-nc 4.0) which permits any noncommercial use, distribution, and reproduction in any medium, provided the original author(s) and source are credited. water had infiltrated but this circumstance does not have a great impact on calculation of $K_{s}$. A falling-head one-dimensional ponded infiltration process is not recommended to estimate $\alpha^{*}$. The theoretical depth of the wetting front can approximately be predicted before the run. The SFH technique appears a rather robust method to simply and rapidly determine $K_{S}$.

\section{Introduction}

The saturated soil hydraulic conductivity, $K_{s}$, can be determined by a falling-head one-dimensional infiltration process (Philip, 1992). The simplified falling-head (SFH) technique (Bagarello et al., 2004; Angulo-Jaramillo et al., 2016) consists of applying a small volume of water on the surface of a confined soil volume and then measuring the time, $t_{a}$, from the application of water to the moment at which the surface area is no longer covered by water. The experiment can be carried out both in the field and on laboratory soil columns. Calculation of $K_{S}$ requires an independent estimation of the so-called $\alpha^{*}$ parameter on the basis of the soil textural and structural characteristics (Elrick and Reynolds, 1992). If the drop of the water level is monitored in some detail during the transient infiltration run, an estimate of $\alpha^{*}$ can also be obtained by the two-level (TL) analysis (Bagarello et al., 2006). An interest of the scientific community for the SFH determination of $K_{S}$ is documented (Keller et al., 2012; Biddoccu et al., 2016, 2017; Kováŕ et al., 2017; Preti et al., 2018).

Methods for measuring $K_{S}$ should be evaluated carefully to ensure that they provide practicable results. Working in the laboratory on repacked soil samples is a necessary, non-exclusive, step of a method's evaluation because the available analytical solutions were developed for an idealized soil and using homogeneous porous media is expected to make interpretation of the data easier. Several topics deserving testing and developments can be identified with reference to the SFH technique and, more in general, falling-head one-dimensional infiltration methodologies.

In the field, the used water volume, $V$, must assure one-dimensional infiltration and therefore it depends, for a given soil surface area, $A$, on the ring insertion depth and the available pore space in the confined soil volume. In theory, the initial depth of ponding, $D$ $=V / A$, is established instantaneously on the soil surface and infiltration starts under a ponded depth of water of $D$. In practice, pouring water needs a few seconds during which infiltration occurs with smaller ponded depths of water. Bagarello et al. (2004) suggested that using $D=V / A$ was a generally reasonable assumption to calculate $K_{S}$ but alternative ways to obtain $D$ should be tested.

Water volume effects on the $K_{S}$ values obtained with the SFH technique have to be determined because, for given experimental conditions, more water implies deeper sampling depths, more 
opportunities for disturbance of the exposed soil surface during water application and higher hydrostatic pressures at the beginning of the run that could have some soil compaction effect.

In their laboratory test of the one-dimensional falling-head infiltration procedure, Bagarello et al. (2006) detected a rather frequent increase of the infiltration rates during the last part of the process, i.e. for ponded heads close to zero, and they suggested that this phenomenon, also signaled by Wang et al. (1998), was a consequence of the removal of entrapped air bubbles close to the end of the process. The SFH technique is used on initially unsaturated soils. Therefore, establishing if this phenomenon is frequent and determining its impact on $K_{S}$ determination is important, taking into account that, with the SFH technique, only $t_{a}$ is measured. In other words, the technique is not suited to signal any change in infiltration rates during the run.

The TL analysis is computationally and experimentally complicate because cumulative infiltration has to be determined at many times during the falling-head run (Bagarello et al., 2006). This circumstance implies that a TL-type experiment has a limited applicability in the field. An alternative way having some practical interest for field estimation of $\alpha^{*}$ could be to develop a methodology requiring a very limited information on the falling-head infiltration process. An approach of this kind, making use of only two measurements of the infiltration time during the run, was developed by Philip (1993) for the Philip-Dunne permeameter.

Finally, the depth of the wetting front at the end of the SFH experiment has to be predicted before the run to be confident that infiltration will be one-dimensional during the run. An analysis of true depths of wetting front appears advisable since a difference between predicted and actual depths of the wetting front could imply a violation of theory during the method's application. In particular, infiltration becomes three-dimensional if the wetting front crosses the bottom of the confined soil volume.

The general objective of this investigation was to check in the laboratory falling-head one-dimensional infiltration procedures for saturated soil hydraulic conductivity, $K_{S}$, determination. The specific objectives were to: i) test water volume effects on $K_{S}$ determination for three homogeneous soils; ii) compare the $K_{S}$ values for these three media; iii) establish the impact of an increasing final infiltration rate on $K_{S}$ calculations; iv) test an experimentally simplified procedure to estimate the $\alpha^{*}$ parameter; and v) establish the reliability of a theoretical prediction of the depth of the wetting front at the end of the SFH run.

\section{Theory}

According to Philip (1958), the Green and Ampt (1911) or delta function (Philip, 1969) model is useful for one-dimensional ponded infiltration. Under falling-head conditions, cumulative infiltration, $I(\mathrm{~L})$, can be described by the following equation that includes gravity:

$$
t=\frac{\Delta \theta}{K_{s}(1-\Delta \theta)}\left[\frac{I(t)}{\Delta \theta}-\frac{D-\psi_{f}}{1-\Delta \theta} \ln \left(1+\frac{(1-\Delta \theta) I(t)}{\Delta \theta\left(D-\psi_{f}\right)}\right)\right]
$$

where $t(\mathrm{~T})$ is the time, $\Delta \theta\left(\mathrm{L}^{3} \mathrm{~L}^{-3}\right)$ is the difference between the saturated $\left(\theta_{s}\right)$ and the initial $\left(\theta_{i}\right)$ volumetric soil water content, $K_{S}$ $\left(\mathrm{L} \mathrm{T}^{-1}\right)$ is the saturated soil hydraulic conductivity (mean conductivity of the wetted region, taken as constant), $D(\mathrm{~L})$ is the height of the ponded head at $t=0$, and $\psi_{f}(\mathrm{~L})$ is the soil water pressure head at the wetting front, with $\psi_{f}$ negative. The $\psi_{f}$ term can be replaced by the so-called $\alpha^{*}\left(\mathrm{~L}^{-1}\right)$ parameter using the following relationship, derived by assuming an exponential hydraulic conductivity - pressure head relationship (Gardner, 1958) and representing $\psi_{f}$ according to Philip (1969) (Reynolds and Elrick, 1990; Elrick et al., 2002):

$$
\alpha^{*} \cong-\frac{1}{\psi_{f}}
$$

Eq.(1) can then be written in the following form:

$$
t=\frac{\Delta \theta}{K_{s}(1-\Delta \theta)}\left[\frac{I(t)}{\Delta \theta}-\frac{D+\frac{1}{\alpha^{*}}}{1-\Delta \theta} \ln \left(1+\frac{(1-\Delta \theta) I(t)}{\Delta \theta\left(D+\frac{1}{\alpha^{*}}\right)}\right)\right]
$$

The depth of the wetting front, $d(\mathrm{~L})$, at a given moment during the falling-head experiment can be estimated as (Bagarello et al., 2004):

$d=\frac{V(t)}{A \Delta \theta}=\frac{I(t)}{\Delta \theta}$

where $V(t)\left(\mathrm{L}^{3}\right)$ is the infiltrated water volume from $t=0$ up to the considered moment and $A\left(\mathrm{~L}^{2}\right)$ is the area of the infiltration surface. Bagarello et al. (2004) used Eq.(3) to propose a SFH technique for determining $K_{s}$. By this technique, a small water volume, $V\left(\mathrm{~L}^{3}\right)$, is quickly poured on the surface of a confined soil volume and total duration of infiltration, $t_{a}(\mathrm{~T})$, is measured. At $t=t_{a}, I\left(t_{a}\right)$ $=D=V / A(\mathrm{~L})$. Then, Eq.(3) solved for $K_{S}$ becomes:

$$
K_{s}=\frac{\Delta \theta}{t_{a}(1-\Delta \theta)}\left[\frac{D}{\Delta \theta}-\frac{\left(D+\frac{1}{\alpha^{*}}\right)}{1-\Delta \theta} \ln \left(1+\frac{(1-\Delta \theta) D}{\Delta \theta\left(D+\frac{1}{\alpha^{*}}\right)}\right)\right]
$$

The need to assure one-dimensional flow during the run implies that, in the field, the $d$ value obtained by Eq.(4) for $t=t_{a}$ has to be smaller than or equal to the ring insertion depth.

Eq.(3) can be used to predict the infiltration time of any water volume during the falling-head process. In particular, it can be applied to determine $t=t_{0.5}$ that is the infiltration time of the first half of the applied water volume, i.e. $I\left(t_{0.5}\right)=D / 2$. The ratio between $t_{a}$ and $t_{0.5}$ is then equal to:

$$
\frac{t_{a}}{t_{0.5}}=\frac{\frac{D}{\Delta \theta}-\frac{D+\frac{1}{\alpha^{*}}}{1-\Delta \theta} \ln \left[1+\frac{(1-\Delta \theta) D}{\Delta \theta\left(D+\frac{1}{\alpha^{*}}\right)}\right]}{\frac{D}{2 \Delta \theta}-\frac{D+\frac{1}{\alpha^{*}}}{1-\Delta \theta} \ln \left[1+\frac{(1-\Delta \theta) D}{2 \Delta \theta\left(D+\frac{1}{\alpha^{*}}\right)}\right]}
$$

Determining $t_{0.5}$ in addition to $t_{a}$ should be rather easy during a falling-head infiltration experiment, even in the field, and it potentially yields an estimate of $\alpha^{*}$ which is the only unknown parameter of Eq.(6). 


\section{Materials and methods}

\section{Laboratory experiment}

A loam soil (USDA classification, Gee and Bauder, 1986) with a maximum particle diameter of $2000 \mu \mathrm{m}$ was used for this investigation. This soil was passed through a $105 \mu \mathrm{m}$ sieve to obtain three different soils to be tested (Table 1): i) 0-2000 soil (diameter of the soil particles, $d_{p}$, varying from 0 to $2000 \mu \mathrm{m}$ ); ii) $0-105$ soil $\left(0<d_{p} \leq 105 \mu \mathrm{m}\right)$; and iii) $105-2000$ soil $\left(105<d_{p} \leq 2000 \mu \mathrm{m}\right)$.

A total of 48 packed soil columns were prepared in graduated Plexiglas tubes (internal diameter $=0.094 \mathrm{~m}$; height $=0.5 \mathrm{~m}$; Figure 1) for each soil type given that the analysis assumes a homogeneous soil (Bagarello et al., 2006). A nylon guard cloth and a wire net were connected to the base of the tube to support the weight of the soil. According to many other laboratory investigations (e.g. Assouline and Narkis, 2011; Moutier et al., 1988; Di Prima et al., 2018), air-dried soil was used to fill the tube to a height of approximately $0.4 \mathrm{~m}$. The soil was then compacted manually by dropping the tube repeatedly from a height of approximately $0.05 \mathrm{~m}$ until compaction ceased. The number of drops varied between 18 and 170, depending on the soil sample, and the final height of the soil columns was in the ranges $0.33-0.35,0.28$ 0.35 and $0.33-0.36 \mathrm{~m}$ (sample volumes of 0.0023-0.0024, 0.00190.0024 and $0.0023-0.0025 \mathrm{~m}^{3}$ ) for the $0-2000,0-105$ and $105-2000$ soils, respectively. For each tube, the weight of the air-dried soil used to fill the tube and the final volume of the soil sample were noted. The gravimetric water content of the air-dried soil was determined on a small soil sample and this water content was assumed to be representative of the whole sample. The dry soil bulk density, $\rho_{b}$, and the volumetric soil water content, $\theta_{i}$, were then calculated and the volumetric saturated soil water content, $\theta_{s}$, was set equal to total porosity obtained from $\rho_{b}$ (Table 1).

A wire mesh was placed on the soil surface and a falling-head infiltration experiment was carried out on each soil column by pouring almost instantly a pre-established water volume, $V$, on the infiltration surface. In particular, the 48 columns filled with a given soil were randomly subdivided into four groups, each constituted by 12 soil columns, and a fixed water volume $(V=280,624,833$ and $940 \mathrm{~cm}^{3}$ ) was used for each group of soil columns. This choice was made to test effects of the initially established ponded depth of water on $K_{S}$ determination for a presumably homogeneous porous medium. The largest water volume avoided emergence of the wetting front from the bottom of the tube since, according to Eq.(4), $d$
$\mathbf{A}$

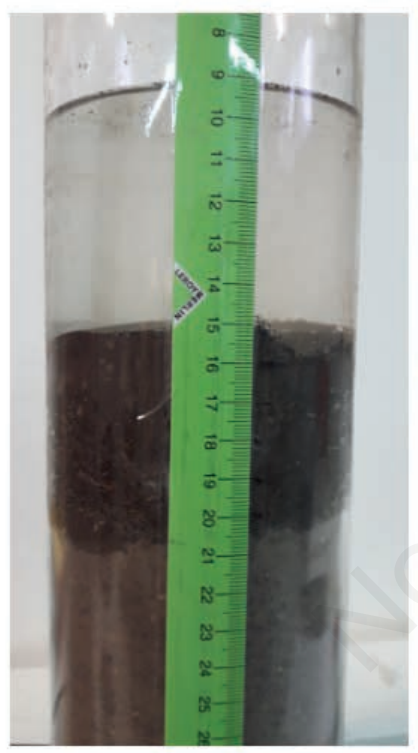

B

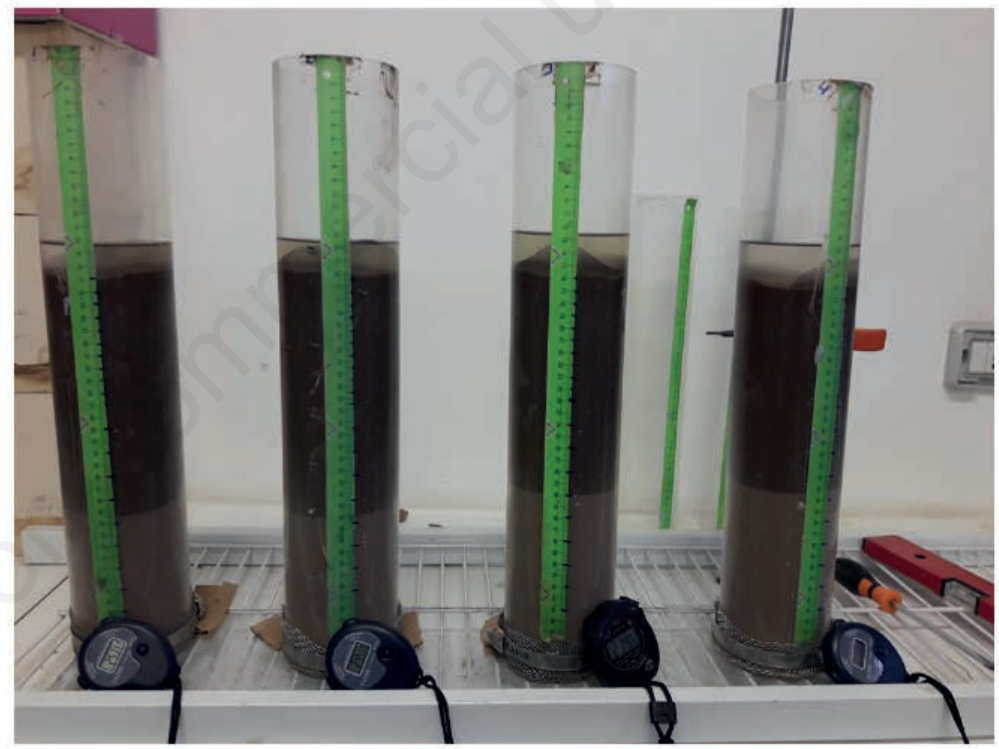

C

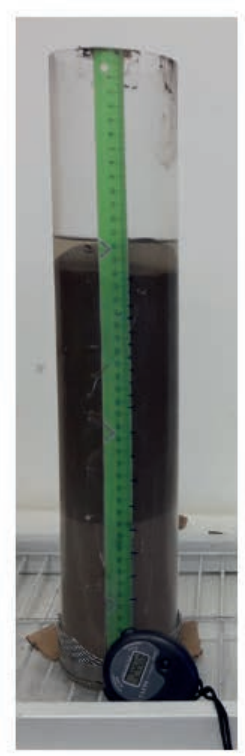

Figure 1. Soil columns during the experiment: A) early-stage; B) close to the end of the experiment; and C) appearance of an air bubble in the final stage of the experiment.

Table 1. Basic statistics of the clay $(c l)$, silt $(s i)$ and sand $(s a)$ percentages (sample size, $N=4$ for each soil), and dry soil bulk density $\left(\rho_{b}\right)$, volumetric soil water content at the beginning of the transient infiltration experiment $\left(\theta_{i}\right)$ and saturated soil volumetric water content $\left(\theta_{s}\right)$ for the soil columns used in the investigation $(N=48$ for each soil).

\begin{tabular}{|c|c|c|c|c|c|c|c|c|c|c|c|c|c|c|c|c|c|c|}
\hline \multirow[t]{2}{*}{ Statistic } & \multicolumn{6}{|c|}{ 0-2000 soil } & \multicolumn{6}{|c|}{ 0-105 soil } & \multicolumn{5}{|c|}{$105-2000$ soil } & \multirow[b]{2}{*}{$\begin{array}{c}\theta_{\mathrm{s}} \\
\left(\mathrm{m}^{3} \mathrm{~m}^{-3}\right)\end{array}$} \\
\hline & $\begin{array}{c}\mathrm{cl} \\
(\%)\end{array}$ & $\begin{array}{l}\text { si } \\
(\%)\end{array}$ & $\begin{array}{c}\text { sa } \\
(\%)\end{array}$ & $\begin{array}{c}\rho \mathrm{\rho b} \\
\left(\mathrm{g} \mathrm{cm}^{-3}\right)\end{array}$ & $\begin{array}{c}\theta_{\mathrm{i}} \\
\left(\mathrm{m}^{3} \mathrm{~m}^{-3}\right)\end{array}$ & $\begin{array}{c}\theta_{s} \\
\left(m^{3} m^{-3}\right)\end{array}$ & $\begin{array}{c}\text { cl } \\
(\%)\end{array}$ & $\begin{array}{c}\text { si } \\
(\%)\end{array}$ & $\begin{array}{c}\text { sa } \\
(\%)\end{array}$ & $\begin{array}{c}\mathrm{\rho b} \\
\left(\mathrm{g} \mathrm{cm}^{-3}\right)\end{array}$ & $\begin{array}{c}\theta_{\mathrm{i}} \\
\left(\mathrm{m}^{3} \mathrm{~m}^{-3}\right)\end{array}$ & $\begin{array}{c}\theta_{s} \\
\left(m^{3} m^{-3}\right)\end{array}$ & $\begin{array}{l}\mathrm{cl} \\
(\%)\end{array}$ & $\begin{array}{c}\text { si } \\
(\%)\end{array}$ & $\begin{array}{c}\text { sa } \\
(\%)\end{array}$ & $\begin{array}{c}\rho b \\
\left(\mathrm{~g} \mathrm{~cm}^{-3}\right)\end{array}$ & $\begin{array}{c}\theta_{\mathrm{i}} \\
\left(\mathrm{m}^{3} \mathrm{~m}^{-3}\right)\end{array}$ & \\
\hline Min & 16.2 & 35.2 & 47.0 & 1.197 & 0.033 & 0.498 & 17.9 & 57.2 & 20.8 & 1.132 & 0.042 & 0.474 & 14.4 & 32.1 & 51.3 & 1.175 & 0.026 & 0.479 \\
\hline Max & 17.2 & 36.4 & 48.6 & 1.330 & 0.068 & 0.548 & 21.5 & 58.3 & 24.9 & 1.394 & 0.144 & 0.573 & 16.1 & 34.2 & 52.5 & 1.381 & 0.075 & 0.557 \\
\hline Mean & 16.7 & 35.7 & 47.6 & 1.254 & 0.049 & 0.527 & 19.7 & 57.6 & 22.7 & 1.199 & 0.061 & 0.547 & 15.4 & 32.7 & 51.9 & 1.281 & 0.045 & 0.517 \\
\hline CV (\%) & 2.5 & 1.4 & 1.5 & 2.7 & 22.1 & 2.4 & 8.0 & 1.0 & 7.5 & 5.3 & 46.8 & 4.4 & 5.2 & 3.1 & 1.0 & 4.2 & 32.1 & 3.9 \\
\hline
\end{tabular}

Min, minimum value; Max, maximum value; Mean, arithmetic mean; CV, coefficient of variation. 
was not expected to exceed 0.29 (0-2000 soil), 0.28 (0-105 soil) and 0.32 (105-2000 soil) $\mathrm{m}$. The drop of the water level during the transient infiltration experiment was monitored visually through the walls of the Plexiglas tube by noting the time corresponding to every subsequent $5 \mathrm{~mm}$ drop. The time, $t_{a}$ (original $\mathrm{SFH}$ experiment), and the actual depth of the wetting front at the end of the run, $d_{m}$, were also visually measured (Figure 1). Vertical soil expansion, $v_{e}$, at the end of infiltration was recorded when it occurred. Initially dry soil was used for the experiments in accordance with Bagarello et al. $(2004,2006)$.

\section{Dataset development}

A dataset was developed for each soil. For each soil column, the dataset comprised $\rho_{b}, \theta_{i}, \theta_{s}, v_{e}$, the measured, $D_{m}$, and the theoretical, $D_{t}=V / A$, ponded depth of water established on the infiltration surface at the beginning of the run, the measured, $d_{m}$, and the theoretical, $d_{t}=I / \Delta \theta$, wetting front depth at the end of the run, $t_{a}$ and $t_{0.5}$. In particular, $D_{m}$ was obtained by the difference between the first reading of the water level above a datum (bottom of the soil column) and the height of the soil surface above the same datum when all water had infiltrated. An alternative way to calculate $D_{m}$ could be considering the height of the soil surface immediately before the run. The $D_{m}$ values do not change if vertical expansion does not occur during the run. Otherwise, considering this position introduces an inconsistency in the $D$ calculations. In particular, at $t=t_{a}$, there is no more water on the soil surface but the calculations would indicate that a layer of water, having a height of $v_{e}$, is still present on this surface.

Eq.(5) with $\alpha^{*}=12 \mathrm{~m}^{-1}$, that is the first approximation value for this parameter (Elrick and Reynolds, 1992; Reynolds and Lewis, 2012), was used to estimate $K_{S}$ by the SFH technique (Bagarello et al., 2004). Both $D_{m}$ and $D_{t}$ were used in the calculations, and the corresponding $K_{S}$ values where denoted by $K_{S, m}$ and $K_{s, t}$, respectively.

In many cases, plotting the data on a cumulative infiltration, $I$, $v s$ time, $t$, graph suggested an increase of the infiltration rate, $i$, during the last part of the infiltration process, i.e., for ponded heads close to zero. Therefore, two $i$ estimates at, $i_{e}$, and near, $i_{n e}$, the end of the run were obtained for each soil column by linear regression of selected $(I, t)$ data pairs (Figure 2 ). In particular, $i_{e}$ was obtained by considering the last two or three data points (only occasionally a few more), depending on the visually detected signs about the final increase of $i$. The estimate of $i_{n e}$ was obtained by considering the two or three $(I, t)$ data points immediately preceding those signaling the infiltration rate increase. Eq.(3) with $\alpha^{*}=12 \mathrm{~m}^{-1}$ was solved for $K_{S}$ and it was applied to obtain an estimate of $K_{S}$, denoted by the symbol $K_{s, n e}$, for an infiltration process starting at $t=0$ and going on till collecting the last of the $(I, t)$ data points that did not signal any $i$ increase.

Eq.(6) was used in an attempt to obtain an estimate of $\alpha^{*}$ for each soil column. At this aim, the theoretical $t_{a} / t_{0.5}$ ratio was calculated for different $\alpha^{*}$ values, ranging from 1 to $100 \mathrm{~m}^{-1}$ with steps of $1 \mathrm{~m}^{-1}$. The $\alpha^{*}$ value yielding the best agreement between the theoretical and the experimentally determined $t_{a} / t_{0.5}$ ratio was assumed to be the specific $\alpha^{*}$ parameter for the soil column. Estimation of $\alpha^{*}$ was considered to be unsuccessful when the best agreement for $t_{a} / t_{0.5}$ was detected with reference to one of the two extremes of $\alpha^{*}$. A smaller range of $\alpha^{*}$ values was considered in this investigation as compared with Bagarello et al. (2006) $(0.1 \leq$ $\alpha^{*} \leq 1000 \mathrm{~m}^{-1}$ in that case) since $\alpha^{*}$ for the considered soils should not be smaller than $1 \mathrm{~m}^{-1}$ and larger than $100 \mathrm{~m}^{-1}$ (Elrick and Reynolds, 1992; Reynolds and Lewis, 2012) and the investigation by Bagarello et al. (2006) was consistent with this expectancy.

\section{Data analysis}

A comparison was initially carried out between the measured, $D_{m}$, and the theoretical, $D_{t}$, ponded depths of water at the beginning of the SFH run. Then, the impact of $D$ on $K_{S}$ calculation by Eq.(5) was determined by comparing $K_{s, m}$ and $K_{s, t}$. The difference between the two estimates of $K_{S}$ for a given run was considered to be negligible when their ratio fell in the 0.75 to 1.25 range (Reynolds, 2013) but it was also taken into account that differences by a factor of two or three could be considered small for some practical purposes (Elrick and Reynolds, 1992).

The effect of the used water volume for the run on $K_{S}$ determination was then checked for each soil. In particular, a regression analysis between $K_{S}\left(K_{s, m}, K_{s, t}\right)$ and $D\left(D_{m}\right.$ and $D_{t}$, respectively) was carried out. Linear, logarithmic, power and exponential relationships were considered and the relationship with the highest coefficient of determination, $R^{2}$, was retained for the analysis. The Tukey honestly significant difference (THSD) test at $\mathrm{P}=0.05$ was also applied to compare $K_{S}$ values obtained with the four water volumes. A soil comparison was then carried out with reference to both $K_{s, m}$ and $K_{s, t}$. This analysis was carried out by considering the complete datasets for each soil (i.e., regardless of the used water volume) but also by extracting from the complete dataset the runs corresponding to a given $V$ value. In both cases, a pairwise twotailed t test at $\mathrm{P}=0.05$ was used to compare the three soils.

The next step was to analyze the final phase of the run, when ponded heads approach zero. The increase of $i$ at the end of the run was quantified by the ratio $i_{e} / i_{n e}$ and its impact on $K_{S}$ calculation was checked by comparing $K_{s, m}$ with $K_{s, n e}$.

The estimated $\alpha^{*}$ values were summarized for each soil and the conditions discriminating between valid and invalid runs in terms of $\alpha^{*}$ estimation were identified by an analysis of $t_{a} / t_{0.5}$.

Finally, a comparison between the actual, $d_{m}$, and the theoretical, $d_{t}$, depths of the wetting front at the end of the run was carried out.

\section{Results and discussion}

\section{Theoretical vs measured ponded depth of water}

The length of the soil column increased upon wetting in 37 (02000 soil $), 14$ (0-105 soil) and 40 (105-2000 soil) cases and, on average, $v_{e}$ was equal to $4.6(C V=70.6 \%), 2.4(C V=177.4 \%)$, and $5.1(C V=58.9 \%) \mathrm{mm}$, respectively. A length increase after wetting

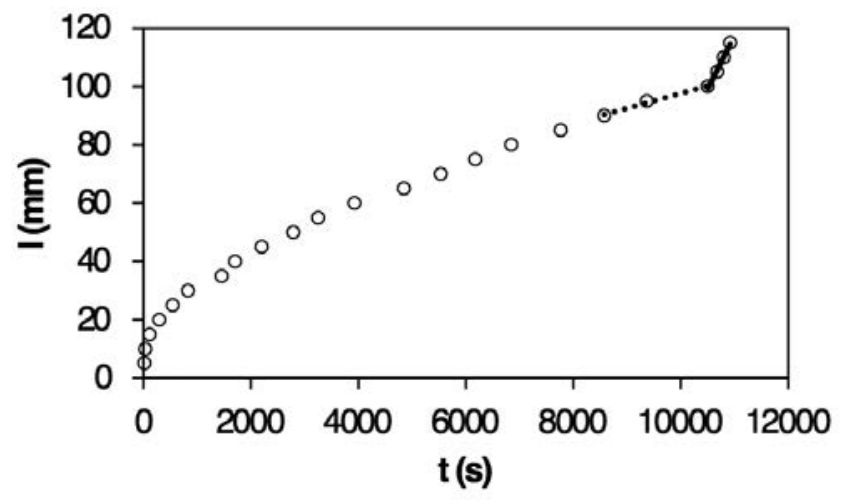

Figure 2. Example of infiltration rates calculation at $\left(i_{e}\right.$, continuous line) and near ( $i_{n e}$, dotted line) the end of the run on a cumulative infiltration, $I$, versus time, $t$, plot. 
was also noticed as a consequence of soil swelling by other authors (Moutier et al., 1998).

The theoretical ponded depth of water at the beginning of the run, $D_{t}$, varied between 40.5 and $135.5 \mathrm{~mm}$, depending on the applied water volume, and $D_{m}$ was in the range 35 to $135 \mathrm{~mm}$ for the $0-105$ soil and $30-130 \mathrm{~mm}$ for the other two soils. A $D_{m} / D_{t}$ ratio $\leq 1$ was the most frequent result since $D_{m} / D_{t}>1$ was obtained for only the $6.3 \%$ of the 144 runs. The mean of $D_{m} / D_{t}$ was closest to one for the $0-105$ soil (0.96) and it was significantly lower (0.880.89 ) for the $0-2000$ and 105-2000 soils (Table 2).

A $D_{m}$ value slightly smaller than $D_{t}$ can be explained by considering that the first water level reading was unavoidably made a few seconds after water started to infiltrate the soil. Moreover, $D_{m}$ is smaller than $D_{t}$ if vertical soil expansion occurs during infiltration. Starting from the beginning of water application, many small air bubbles were often detectable in the applied water volume and, in several cases, they remained encapsulated in the water until infiltration finished. The presence of these air bubbles in the water was likely responsible of the rare detection of $D_{m} / D_{t}>1$.

A higher $D$ value for $t=t_{a}$ means that more water infiltrates the soil. Consequently, $K_{s, t} / K_{s, m} \geq 1$ was the most frequent result. This ratio was closest to one for the $0-105$ soil and it was significantly higher for the other two soils (Table 2). On average, however, all differences between two estimates of $K_{s}$ were negligible since the mean $K_{s, t} / K_{s, m}$ ratios varied from 1.06 to 1.21 , depending on the soil. For each soil, the $K_{S}$ differences were generally negligible even at the single run level since $0.75 \leq K_{s, t} / K_{s, m} \leq 1.25$ was obtained in the $65 \%$ or more of the cases (Table 2). The $R^{2}$ values of the linear regression line between $K_{s, t}$ and $K_{S, m}$ varied with the soil from 0.91 (0-105 soil) to $0.97(0-2000$ soil $)$ and they were statistically significant in all cases according to a two-tailed t test at $P=0.05$ (Glantz, 2012). However, none of the linear regression lines did coincide with the identity line according to the calculated $95 \%$ confidence intervals for the intercept and the slope. Using $D_{t}$ for the $K_{S}$ calculations is common in field application of the SFH technique but water is not

Table 2. Basic statistics of the $D_{m} / D_{t}$ ratio $\left(D_{m}\right.$ and $D_{t}=$ measured and theoretical ponded depth of water at the beginning of the run, respectively), the $K_{s, m} / K_{s, t}$ ratio $\left(K_{s, m}\right.$ and $K_{s, t}=$ saturated soil hydraulic conductivity estimated by the SFH equation using $D_{m}$ and $D_{t}$, respectively), and the $K_{s, t}$ and $K_{s, m}$ values obtained on the three tested soils (sample size, $N=48$ for each soil).

\begin{tabular}{|c|c|c|c|c|}
\hline Variable & Statistic & $0-2000$ soil & 0-105 soil & $105-2000$ soil \\
\hline \multirow{4}{*}{$\mathrm{D}_{\mathrm{m}} / \mathrm{D}_{\mathrm{t}}$} & Min & 0.74 & 0.81 & 0.74 \\
\hline & $\operatorname{Max}$ & 1.00 & 1.24 & 1.11 \\
\hline & Mean & $0.89^{a}$ & $0.96^{\mathrm{b}}$ & $0.88^{a}$ \\
\hline & CV (\%) & 5.7 & 8.6 & 9.2 \\
\hline \multirow[t]{5}{*}{$\mathrm{K}_{\mathrm{s}, \mathrm{t}} / \mathrm{K}_{\mathrm{s}, \mathrm{m}}$} & Min & 1.00 & 0.72 & 0.85 \\
\hline & Max & 1.60 & 1.31 & 1.61 \\
\hline & Mean & $1.18^{\mathrm{a}}$ & $1.06^{\mathrm{b}}$ & $1.21^{\mathrm{a}}$ \\
\hline & CV (\%) & 8.8 & 11.5 & 13.1 \\
\hline & $P_{0.75-1.25}(\%)$ & 85.4 & 87.5 & 64.6 \\
\hline \multirow[t]{4}{*}{$\mathrm{K}_{\mathrm{s}, \mathrm{t}}\left(\mathrm{mm} \mathrm{h}^{-1}\right)$} & Min & 6.8 & 5.0 & 19.2 \\
\hline & Max & 132.5 & 39.3 & 381.4 \\
\hline & Mean & $32.2^{\mathrm{a}}$ & $17.1^{\mathrm{b}}$ & $80.9 c$ \\
\hline & CV (\%) & 64.5 & 53.9 & 72.3 \\
\hline \multirow[t]{4}{*}{$\mathrm{K}_{\mathrm{s}, \mathrm{m}}\left(\mathrm{mm} \mathrm{h}^{-1}\right)$} & Min & 5.8 & 4.3 & 17.3 \\
\hline & Max & 106.0 & 42.6 & 237.6 \\
\hline & Mean & $27.0^{\mathrm{a}}$ & $16.6^{\mathrm{b}}$ & $65.5^{c}$ \\
\hline & CV (\%) & 59.8 & 60.8 & 62.0 \\
\hline
\end{tabular}

Min, minimum value; Max, maximum value; Mean, arithmetic mean; $\mathrm{CV}$, coefficient of variation; $P_{0.75-1.25}=$ number of cases, in percentage of the total number of cases, for which $K_{s, \ell}, K_{s, m}$ was in the range 0.75 to 1.25. For a given variable, mean values followed by a different letter are significantly different according to a pairwise two-tailed t test at $\mathrm{P}=0.05$. Means followed by the same letter are not significantly different. poured instantly on the soil surface and possible changes in the height of the soil column during the run cannot be taken into account. These changes were considered with $D_{m}$ but the initial stage of the infiltration process (i.e., the first few seconds) was neglected in this case. The estimates of $K_{s}$ obtained with $D_{t}$ and $D_{m}$ did not coincide but, on the whole, the differences between $K_{s, m}$ and $K_{s, t}$ were small or even very small, indicating a practical similarity of the two ways to estimate $D$ for the SFH equation.

\section{Effect of ponded depth of water on saturated soil hydraulic conductivity}

Regardless of the use of the measured $\left(D_{m}\right)$ or the theoretical $\left(D_{t}\right)$ ponded depth of water for the $K_{S}$ calculations, a statistically significant effect of $D$ on $K_{S}\left(K_{s, m}, K_{s, t}\right)$ was detected for the 0-2000 and $0-105$ soils, with $K_{S}$ values decreasing as $D$ increased in both cases (Figure 3 ). This effect was particularly clear for the latter soil
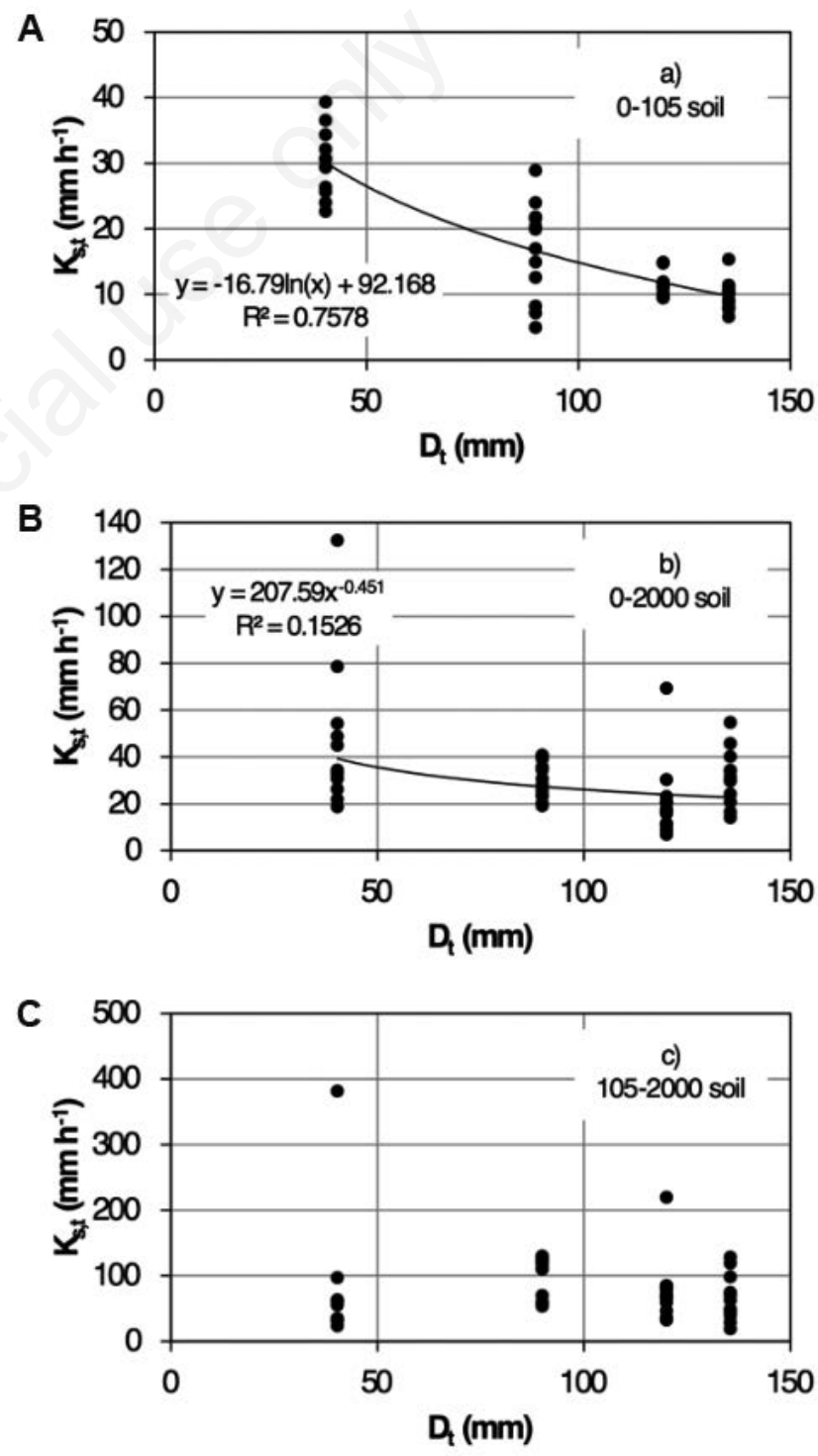

Figure 3. Saturated soil hydraulic conductivity calculated with the simplified falling-head equation, $K_{s, t}$, against the theoretically established ponded depth of water at the beginning of the infiltration run, $D_{t}$ : A) $0-105$ soil; B) $0-2000$ soil; and C) 105 2000 soil. 
( $R^{2}=0.67-0.76$, depending on the used $D$ value) and it appeared rather weak for the former one, since the $\left(K_{s}, D\right)$ data points were highly scattered in this case $\left(R^{2}=0.15\right)$. According to the fitted $K_{s, t}$ vs $D_{t}$ relationships, an increase of $D$ from 40 to $135 \mathrm{~mm}$ determined a decrease of $K_{S}$ by 3.1 times for the $0-105$ soil and by 1.7 times for the $0-2000$ soil. An effect of $D$ on $K_{S}$ was not detected for the 105-2000 soil $\left(R^{2}=0.006-0.01\right)$.

The results of the THSD test (Table 3) were similar to those obtained by the regression analysis. In particular, a single difference out of six established comparisons was detected for the 02000 soil. For the $0-105$ soil, larger water volumes clearly yielded smaller $K_{S, m}$ and $K_{S, t}$ values, with non-significant $K_{S}$ differences only with reference to the two largest $V$ values. The used water volume did not influence the two estimates of $K_{S}$ for the 105-2000 soil.

Therefore, the ponded depth of water effect was soil specific since using more water for the SFH run implied measurement of smaller $K_{S}$ values for the finest soil, had a small and almost negligible effect on $K_{S}$ determination for the intermediate soil, and was uninfluential for the coarsest soil. An inverse relationship between $K_{S}$ and $D$, such as the one detected for the $0-105$ soil, could be due to the fact that a higher hydrostatic pressure at the beginning of the run determined more compaction of the surface soil layer and hence lower conductivity values. Therefore, it could be suggested that the 105-2000 soil was the most stable soil among those tested whereas the $0-105$ soil was the most unstable one. However, more water for the run implies larger sampling depths. Therefore, an inverse $K_{S} v s D$ relationship could also be a consequence of vertical gradients in soil bulk density, increasing from the surface layer to the bottom, perhaps even due to the downward particle migration during infiltration. Slight differences in soil bulk density resulting from differences in packing were reported in other investigations (Assouline and Narkis, 2011). If this was the cause, gradients in packing density occurred in the finest soil but they were less relevant or even absent in coarser soil conditions. Finally, the accuracy of the Green and Ampt (1911) model is expected to increase with the ponded depth of water on the soil surface (Philip, 1992). Therefore, it could also be suggested that more accurate $K_{S}$ values were obtained in the finest soil with the largest $D$ values. Instead, nothing can be said about $K_{S}$ accuracy for the coarsest soil since an effect of $D$ was not detected in this case.

\section{Comparing soils}

According to a pairwise two-tailed t test at $\mathrm{P}=0.05$, the $\mathrm{SFH}$ technique was able to statistically discriminate among the three soils, regardless of the considered ponded depth of water for the calculations $\left(D_{m}, D_{t}\right)$, since the highest mean $K_{s}$ value (65.5-80.9 $\mathrm{mm} \mathrm{h}^{-1}$, depending on $D$ ) was obtained for the 105-2000 soil, only containing relatively coarse particles, the lowest mean (16.6-17.1 $\mathrm{mm} \mathrm{h}^{-1}$ ) was detected for the $0-105$ soil, with only relatively fine particles, and an intermediate result (27.0-32.2 $\mathrm{mm} \mathrm{h}^{-1}$ ) was obtained for the $0-2000$ soil, constituted by both coarse and fine particles (Table 2).

This comparison was based on the premise that the three $K_{s, m}$ (or $K_{s, t}$ ) datasets were comparable since they were developed by using exactly the same experimental methodology and procedures for each soil. An alternative way to establish a comparison among the three soils was to only consider each time the runs corresponding to a given applied water volume. Therefore, the soil comparison was repeated four times for a given variable $\left(K_{S, m}, K_{S, t}\right)$, i.e. for $V=280,624,833$ and $940 \mathrm{~cm}^{3}$. With this choice, cases with both negligible and appreciable $V$ effects on $K_{S}$ were not pooled together and soil layers that did not vary very much from soil to soil were considered (Table 3). However, each comparison was based on a smaller dataset ( $\mathrm{N}=12$ for each soil) as compared with that performed with the complete datasets $(\mathrm{N}=48$ for each soil).

Regardless of both the considered variable $\left(K_{s, m}\right.$ or $\left.K_{s, t}\right)$ and the used water volume for the run, the numerically highest and lowest mean $K_{S}$ values were obtained in the coarsest (105-2000) and the finest (0-105) soils, respectively (Table 3$)$. The soil differences

Table 3. Mean and coefficient of variation, $C V$, of the saturated hydraulic conductivity values, $K_{s}$, obtained by using different water volumes, $V$, for the SFH run and of the measured depth of the wetting front at the end of the run, $d_{m}$ (sample size, $N=12$ for given variable, soil and water volume).

\begin{tabular}{|c|c|c|c|c|c|c|}
\hline Variable & Soil & Statistic & $\mathrm{V}=280 \mathrm{~cm}^{3}$ & $\mathrm{~V}=624 \mathrm{~cm}^{3}$ & $\mathrm{~V}=833 \mathrm{~cm}^{3}$ & $\mathrm{~V}=940 \mathrm{~cm}^{3}$ \\
\hline $\mathrm{K}_{\mathrm{s}, \mathrm{m}}\left(\mathrm{mm} \mathrm{h}^{-1}\right)$ & $\begin{array}{l}0-2000 \\
0-105 \\
105-2000\end{array}$ & $\begin{array}{c}\text { mean } \\
\text { CV }(\%) \\
\text { mean } \\
\text { CV (\%) } \\
\text { mean } \\
\text { CV (\%) }\end{array}$ & $\begin{array}{c}37.6^{\mathrm{aA}} \\
62.5 \\
31.1^{\mathrm{aA}} \\
22.2 \\
59.4^{\mathrm{aA}} \\
97.9\end{array}$ & $\begin{array}{c}25.2^{\mathrm{ab} \mathrm{A}} \\
26.3 \\
15.5^{\mathrm{b} \mathrm{B}} \\
46.4 \\
77.5^{\mathrm{a} C} \\
34.5\end{array}$ & $\begin{array}{c}18.1^{\mathrm{bA}} \\
82.1 \\
10.8^{\mathrm{bc} A} \\
18.2 \\
64.9^{\mathrm{a} B} \\
66.8\end{array}$ & $\begin{array}{c}27.4^{\mathrm{ab} \mathrm{A}} \\
34.9 \\
9.1^{\mathrm{c} \mathrm{B}} \\
17.0 \\
60.1^{\mathrm{aC}} \\
48.0\end{array}$ \\
\hline $\mathrm{K}_{\mathrm{s}, \mathrm{t}}\left(\mathrm{mm} \mathrm{h}^{-1}\right)$ & $\begin{array}{l}0-2000 \\
0-105 \\
105-2000\end{array}$ & $\begin{array}{c}\text { mean } \\
\text { CV }(\%) \\
\text { mean } \\
\text { CV }(\%) \\
\text { mean } \\
\text { CV }(\%)\end{array}$ & $\begin{array}{c}46.4^{\mathrm{aA}} \\
68.3 \\
30.1^{\mathrm{aA}} \\
16.7 \\
78.0^{\mathrm{a} A} \\
125.3\end{array}$ & $\begin{array}{c}30.1^{\mathrm{ab} \mathrm{A}} \\
26.2 \\
16.8^{\mathrm{b} B} \\
43.9 \\
100.7^{\mathrm{aC}} \\
30.5\end{array}$ & $\begin{array}{c}21.0^{\mathrm{bA} A} \\
78.8 \\
11.5^{\mathrm{cd} A} \\
15.6 \\
77.5^{\mathrm{a} B} \\
62.3\end{array}$ & $\begin{array}{c}31.3^{\mathrm{ab} A} \\
37.7 \\
9.9^{\mathrm{d} B} \\
22.4 \\
67.3^{\mathrm{a} C} \\
50.5\end{array}$ \\
\hline $\mathrm{d}_{\mathrm{m}}(\mathrm{cm})$ & $\begin{array}{l}0-2000 \\
0-105 \\
105-2000\end{array}$ & $\begin{array}{c}\text { mean } \\
\text { CV }(\%) \\
\text { mean } \\
\text { CV }(\%) \\
\text { mean } \\
\text { CV }(\%)\end{array}$ & $\begin{array}{c}11.0 \\
9.5 \\
9.8 \\
4.0 \\
11.4 \\
9.5\end{array}$ & $\begin{array}{c}24.3 \\
9.8 \\
20.4 \\
13.8 \\
26.4 \\
8.9\end{array}$ & $\begin{array}{c}28.2 \\
8.8 \\
23.8 \\
2.4 \\
27.7 \\
11.6\end{array}$ & $\begin{array}{c}28.5 \\
5.3 \\
27.2 \\
5.8 \\
30.3 \\
2.9\end{array}$ \\
\hline
\end{tabular}

$K_{s, m}=$ saturated soil hydraulic conductivity obtained by using Eq.(5) and the measured ponded depth of water at the beginning of the run, $D_{m} . K_{s, t}=$ saturated soil hydraulic conductivity obtained by using Eq.(5) and the theoretically determined value of the ponded depth of water at the beginning of the run, $D_{t}$. For given variable and soil, mean values in a row followed by a different lower-case letter are significantly different according to the Tukey honestly significant difference test at $\mathrm{P}=0.05$. For given water volume and variable, mean values in a column followed by a different upper-case letter are significantly different according to a pairwise two-tailed test at $\mathrm{P}=0.05$. 
were not statistically significant for $V=280 \mathrm{~cm}^{3}$ and with reference to another comparison $\left(V=833 \mathrm{~cm}^{3}, 0-2000\right.$ soil vs $0-105$ soil) and they were statistically significant in all the other cases. Therefore, the expected discrimination among the three soils was generally detectable by using a fixed water volume for the runs and a smaller number of replicated runs. Applying large or relatively large water volumes for the infiltration run appeared appropriate to perceive these soil differences. A possible reason of this result is that more water for the run implies a larger, and presumably more representative, sampled soil volume. Another factor to be considered is that the measurement errors can be expected to have a larger impact on $K_{S}$ calculation for smaller water volumes.

The detected $K_{S}$ differences among soils were consistent with those expected on the basis of their textural characteristics, that likely had a noticeable influence on water permeability of the three soils since they were intentionally structureless or with little structure.

\section{Infiltration rate for ponded heads close to zero}

Increasing infiltration rates during the last part of the infiltration process, i.e. for ponded heads close to zero, were obtained very frequently in this investigation (Figure 2 ). In particular, $i_{e}$ was greater than $i_{n e}$ for 40 to 44 runs, depending on the soil. The mean of $i_{e} / i_{n e}$ varied between 1.9 and 2.6 with some significant, although relatively small, differences among the three tested soils (Table 4). A possible explanation of the increase of infiltration rates close to the end of the run could be that air bubbles entrapped in the upper zone of the soil volume escaped from the soil surface as the hydrostatic pressure due to the ponded head tended to vanish (Bagarello et al., 2006; Figure 1).

The measured ponded depths of water were considered for calculating both $K_{s, m}$ and $K_{s, n e}$ and the former values were $0.78-1.63$ times the corresponding latter values (Table 4). The 0-2000 and 105-2000 soils were characterized by a statistically similar $K_{s, m} / K_{s, n e}$ ratio (1.09-1.13), slightly higher than that detected for the $0-105$ soil, equal to 1.05 . Moreover, $K_{s, m} / K_{s, n e}$ fall in the range $0.75-1.25$ in the $92.4 \%$ of the cases.

According to the similarity criterion by Reynolds (2013), the abrupt change of the infiltration rate close to the end of the run had a minor, and therefore negligible, impact on calculation of $K_{S}$, which means that the SFH determination of $K_{S}$ was not appreciably affected by the final increase of the infiltration rate. This is a practically relevant result since it is practically impossible to detect an increase of the infiltration rate at the end of the SFH field run.

\section{Estimating the $\alpha^{*}$ parameter}

Using Eq.(6) for estimating $\alpha^{*}$ was successful in a limited number of cases, increasing from only five for the $0-105$ soil ( $10.4 \%$ of the runs) to 18 for the $105-2000$ soil $(37.5 \%$, Table 4$)$. The experimental ratio between $t_{a}$ and $t_{0.5}$ influenced the possibility to obtain valid $\alpha^{*}$ estimates. In particular, considering all infiltration runs, i.e. regardless of the soil $(N=144)$, the procedure was always successful for $3.31 \leq t_{a} / t_{0.5} \leq 3.78$ and always unsuccessful for $t_{a} / t_{0.5} \leq 3.16$ and $t_{a} / t_{0.5} \geq 3.94$. For intermediate $t_{a} / t_{0.5}$ values $\left(3.19 \leq t_{a} / t_{0.5} \leq 3.29\right.$ and $\left.3.80 \leq t_{a} / t_{0.5} \leq 3.93\right)$, both success and failure in the $\alpha^{*}$ estimation were detected.

Notwithstanding this, the means of the few valid estimates of $\alpha^{*}$ fell within the range of reasonable $\alpha^{*}$ values (Elrick and Reynolds, 1992) and the soil differences were also reasonable given that higher $\alpha^{*}$ results were obtained in the coarser-textured soil than the finer-textured ones (17 against approximately $9 \mathrm{~m}^{-1}$, Table 4).
These results provided additional support to the suggestion that a ponding infiltration run does not represent the best way to estimate $\alpha^{*}$ (Bagarello et al., 2006; Reynolds and Elrick, 1990). In other terms, $\alpha^{*}$ should be determined independently.

\section{Actual depth of the wetting front}

In general, wetting fronts were easily detectable during the experiments and they exhibited a nearly horizontal shape, probably because a homogeneous porous medium was used in this investigation (Figure 1). The actual depth of the wetting front at the end of the run, $d_{m}$, was generally (i.e., in the $75 \%$ or more of the cases, depending on the soil) greater than the theoretical value, $d_{t}$, that was calculated by Eq.(4) for $t=t_{a}$ (Table 4) but outflow from the bottom of the column was never detected. On average, the $d_{m} / d_{t}$ ratio was in a rather narrow range, relatively close to one (1.061.21 ), for all soils but this ratio was significantly lower for the 0 105 soil than the other two soils. Moreover, $d_{m} / d_{t}$ was found to decrease as $D_{m}$ increased, approximately assuming, in all cases, values close to unity for the largest $D_{m}$ values (Figure 4) $\left(R^{2} \geq\right.$ 0.3725 depending on the soil, $R>0$ in all cases).

Perhaps, a $d_{m} / d_{t}$ ratio greater than one was a consequence of air entrapment in the sampled soil volume. This phenomenon likely occurred in this investigation, as revealed by the final increase in infiltration rates. Consequently, it could be suggested that $d_{m} / d_{t}$ was generally greater than one because some of the pore space was occupied by air instead of water. More water for the run, i.e. larger $D_{m}$ values, implied more opportunities for air displacement during the infiltration process and hence $d_{m} / d_{t}$ values closer to one. Even diffusion of the wetting front could be thought to be a factor determining the observed differences between $d_{m}$ and $d_{t}$.

Table 4. Basic statistics of $i_{e} / i_{n e}\left(i_{e}\right.$ and $i_{n e}=$ infiltration rates at and near the end of the run, respectively), $K_{s, m} / K_{s, n e}$ (saturated soil hydraulic conductivity estimated by considering the complete infiltration process and a process stopped immediately before the raise in infiltration rate, respectively), the experimentally determined $\alpha^{*}$ parameter, and $d_{m} / d_{t}\left(d_{m}\right.$ and $d_{t}=$ measured and theoretical depth of the wetting front at the end of the run, respectively) for the three sampled soils (sample size, $N=48$ for each variable and soil, with an exception for $\alpha^{*}$, as shown in the table).

\begin{tabular}{lcccc}
\hline Variable & Statistic & $0-2000$ soil & $0-105$ soil & $105-2000$ soil \\
ie $/$ ine & Min & 0.59 & 0.46 & 0.55 \\
& Max & 7.0 & 10.6 & 6.0 \\
& Mean & $2.57^{\mathrm{a}}$ & $1.86^{\mathrm{bc}}$ & $2.19^{\mathrm{ac}}$ \\
& $\mathrm{CV}(\%)$ & 66.3 & 81.0 & 49.2 \\
$\mathrm{~K}_{\mathrm{s}, \mathrm{m}} / \mathrm{K}_{\mathrm{s}, \mathrm{ne}}$ & Min & 0.98 & 0.81 & 0.78 \\
& Max & 1.63 & 1.35 & 1.62 \\
& Mean & $1.13^{\mathrm{a}}$ & $1.05^{\mathrm{b}}$ & $1.09^{\mathrm{a}}$ \\
& $\mathrm{CV}(\%)$ & 14.8 & 8.5 & 10.2 \\
\hline$\alpha^{*}\left(\mathrm{~m}^{-1}\right)$ & $\mathrm{N}$ & 14 & 5 & 18 \\
& Min & 2 & 2 & 2 \\
& Max & 20 & 22 & 67 \\
& Mean & 9.3 & 9.2 & 17.0 \\
$\mathrm{~d}_{\mathrm{m}} / \mathrm{d}_{\mathrm{t}}$ & $\mathrm{CV}(\%)$ & 64.7 & 84.0 & 121.6 \\
& Min & 0.91 & 0.66 & 0.88 \\
& Max & 1.45 & 1.30 & 1.55 \\
& Mean & $1.18 \mathrm{a}$ & $1.06 \mathrm{~b}$ & $1.21 \mathrm{a}$ \\
& $\mathrm{CV}(\%)$ & 13.8 & 14.5 & 15.7 \\
& $\mathrm{~N}\left(d_{m} / d_{t}>1\right)$ & $38(79.2 \%)$ & $36(75.0 \%)$ & $42(87.5 \%)$ \\
\hline
\end{tabular}

Min, minimum value; Max, maximum value; Mean, arithmetic mean; $\mathrm{CV}$, coefficient of variation. For a given variable, means followed by a different letter are significantly different according to a two-tailed $t$ test $(\mathrm{P}=0.05)$. Means followed by the same letter are not significantly different. 


\section{Conclusions}

This laboratory investigation increased our knowledge of the factors that can influence application of the SFH technique for saturated soil hydraulic conductivity, $K_{S}$, determination and, more in general, of falling-head one-dimensional infiltration methodologies. A depth of ponding on the infiltration surface at the beginning of the run, $D$, simply calculated by the ratio between the used water volume and the soil surface area does not coincide in general with the depth of ponding that can be determined by visually reading water and soil surface heights above a datum. However, this difference should not be expected to have a great impact on $K_{S}$ calculations which implies that the simplest way to calculate $D$ can be used in practice.
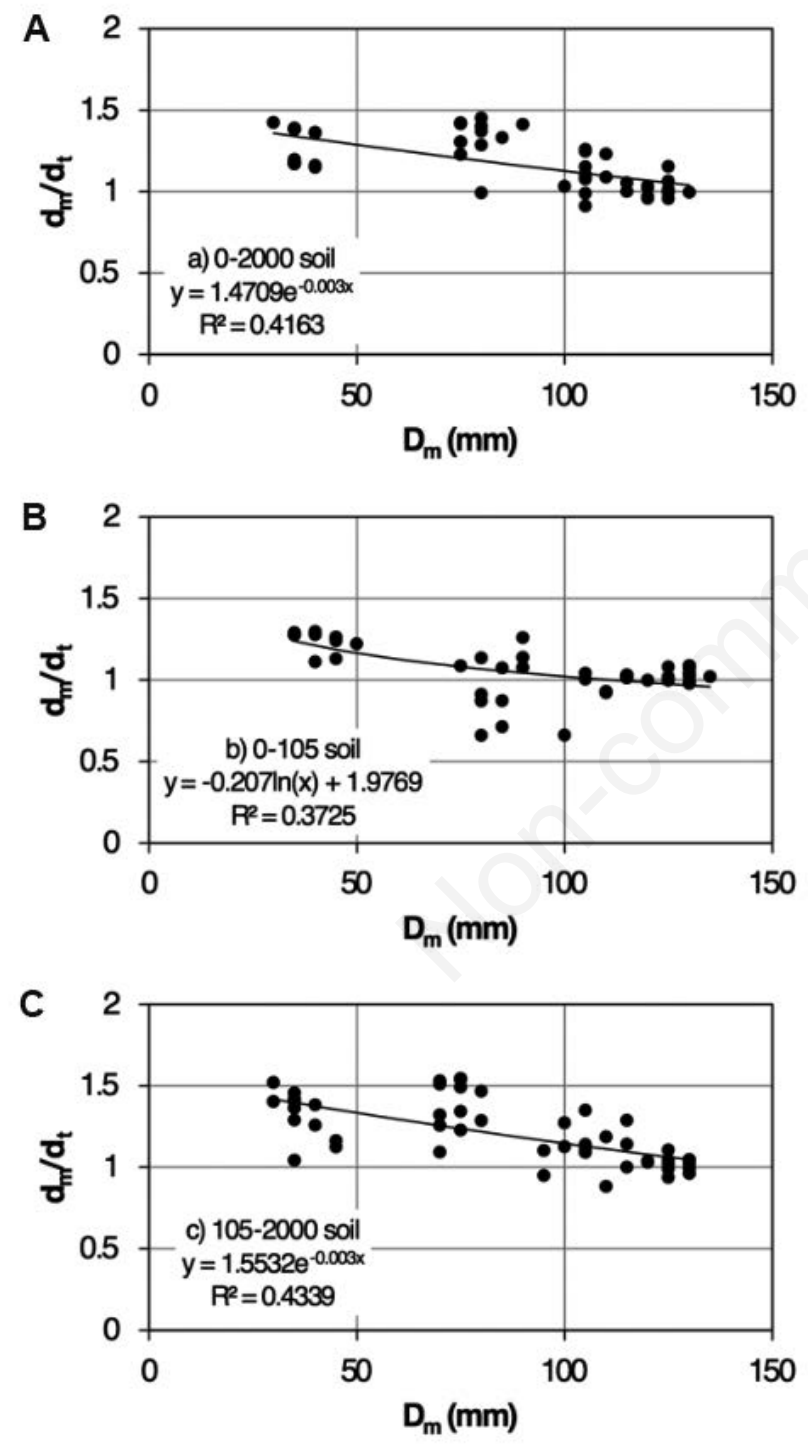

Figure 4. Ratio between the measured, $d_{m}$, and the theoretical, $d_{t}$, depth of the wetting front at the end of the simplified fallinghead run plotted against the measured ponding depth of water at the beginning of the run, $D_{m}$, for the: A) 0-2000 soil; B) 0-105 soil; and C) 105-2000 soil.
Ponded depth of water effects on $K_{S}$ calculation can be detected in nearly homogeneous soil conditions, probably because more compaction of the surface soil layer occurs as a consequence of a greater hydrostatic pressure at the beginning of the run or as a consequence of vertical migration of fine soil particles during the run. Ponded depth of water effects should be expected to occur when the soil contains many mobile small particles but they appear less noticeable or even absent for coarser and more rigid soils.

An abrupt increase of the infiltration rate for ponded heads approaching zero was a very frequent occurrence in this investigation, probably because air bubbles entrapped in the upper zone of the soil volume escaped from the infiltration surface as the hydrostatic pressure due to the ponded head of water tended to vanish. However, the SFH calculations of $K_{S}$ should not be appreciably affected by the final increase of the infiltration rate. Therefore, this phenomenon, that cannot be detected with the SFH experiment, should not be expected to have a strong impact on the $K_{S}$ results.

A falling-head one-dimensional ponded infiltration process does not represent a good means to estimate $\alpha^{*}$ since the run appears to be successful with respect to this objective only in a limited number of cases.

The depth of the wetting front at the end of the run should generally be close to the one calculated theoretically before the run. Even this result supports the SFH procedure since it indicated that a very simple method can be employed to plan a one-dimensional infiltration process. As a precaution, it is recommended to calculate the water volume to be used for the field run by assuming that the ring insertion depth is smaller by a very few centimeters than the actual one.

The information provided by this investigation reinforced our knowledge on the functioning of the SFH technique and it represents a good basis for additional developments. In particular, establishing $K_{S}$ comparisons with other methods and improving our ability to obtain site-specific estimates of $\alpha^{*}$ by simple infiltration experiments appears advisable. Going from nearly idealized porous media to field soil conditions is also necessary because, in this last case, other factors that likely were not relevant in this investigation, such as layering or local heterogeneities, could have a relevant impact on the method's performances. These developments have practical importance since falling-head infiltration procedures can give estimates of $K_{S}$ with experiments that are both parsimonious and rapid.

\section{References}

Angulo-Jaramillo R., Bagarello V., Iovino M., Lassabatere L. 2016. Infiltration measurements for soil hydraulic characterization. Springer International Publishing, Switzerland.

Assouline S., Narkis K. 2011. Effects of long-term irrigation with treated wastewater on the hydraulic properties of a clayey soil. Water Resour. Res. 47:W08530.

Bagarello V., Iovino M., Elrick D.E. 2004. A simplified fallinghead technique for rapid determination of field-saturated hydraulic conductivity. Soil Sci. Soc. Am. J. 68:66-73.

Bagarello V., Elrick D.E., Iovino M., Sgroi A. 2006. A laboratory analysis of falling head infiltration procedures for estimating the hydraulic conductivity of soils. Geoderma 135:322-34.

Biddoccu M., Ferraris S., Opsi F., Cavallo E. 2016. Long-term monitoring of soil management effects on runoff and soil erosion in sloping vineyards in Alto Monferrato (North-West Italy). Soil Till. Res. 155:176-89. 
Biddoccu M., Ferraris S., Pitacco A., Cavallo E. 2017. Temporal variability of soil management effects on soil hydrological properties, runoff and erosion at the field scale in a hillslope vineyard, North-West Italy. Soil Till. Res. 165:46-58.

Di Prima S., Concialdi P., Lassabatere L., Angulo-Jaramillo R., Pirastru M., Cerdà A., Keesstra S. 2018. Laboratory testing of Beerkan infiltration experiments for assessing the role of soil sealing on water infiltration. Catena 167:373-84.

Elrick D.E., Reynolds W.D. 1992. Methods of analyzing constanthead well permeameter data. Soil Sci. Soc. Am. J. 56:320-3.

Elrick D.E., Angulo-Jaramillo R., Fallow D.J., Reynolds W.D., Parkin G.W. 2002. Analysis of infiltration under constant head and falling head conditions. In: Raats P.A.C. et al. (Eds.), Environmental mechanics: Water, mass and energy transfer in the biosphere, Geophysical Monograph Series. AGU, Washington, D.C., 129:47-53.

Gardner W.R. 1958. Some steady-state solutions of the unsaturated moisture flow equation with application to evaporation from a water table. Soil Sci. 85:228-32.

Gee G.W., Bauder J.W. 1986. Particle-size analysis. pp 383-411 in Klute A. (Ed.), Methods of soil analysis. Part 1. Physical and mineralogical methods. 2nd ed. Agronomy no. 9. American Society of Agronomy, Madison, WI, USA

Glantz S.A. 2012. Primer of Biostatistics. 7th ed. The McGrawHill Companies, Inc., New York, NY, USA.

Green W.H., Ampt G.A. 1911. Studies in soil physics. I. The flow of air and water through soils. J. Agr. Sci. 4:1-24

Keller T., Sutter J.A., Nissen K., Rydberg T. 2012. Using field measurement of saturated soil hydraulic conductivity to detect low-yielding zones in three Swedish fields. Soil Till. Res. 124:68-77.
Kovář S., Mašek J., Novák P. 2017. Comparison of tillage systems in terms of water infiltration into the soil during the autumn season. Agron. Res. 15:1629-35.

Moutier M., Shainberg I., Levy G.J. 1998. Hydraulic gradient, aging, and water quality effects on hydraulic conductivity of a Vertisol. Soil Sci. Soc. Am. J. 62:1488-96.

Philip J.R. 1958. The theory of infiltration, 7. Soil Sci. 85:278-86. Philip J.R. 1969. Theory of infiltration. Adv. Hydrosci. 5:215-96.

Philip J.R. 1992. Falling head ponded infiltration. Water Resour. Res. 28:2147-8.

Philip J.R. 1993. Approximate analysis of falling-head lined borehole permeameter. Water Resour. Res. 29:3763-8.

Preti F., Guastini E., Penna D., Dani A., Cassiani G., Boaga J., Deiana R., Romano N., Nasta P., Palladino M., Errico A., Giambastiani Y., Trucchi P., Tarolli P. 2018. Conceptualization of water flow pathways in agricultural terraced landscapes. Land Degrad. Dev. 29:651-62.

Reynolds W.D. 2013. An assessment of borehole infiltration analyses for measuring field-saturated hydraulic conductivity in the vadose zone. Eng. Geol. 159:119-30.

Reynolds W.D., Elrick D.E. 1990. Ponded infiltration from a single ring: I. Analysis of steady flow. Soil Sci. Soc. Am. J. 54:123341.

Reynolds W.D., Lewis J.K. 2012. A drive point application of the Guelph Permeameter method for coarse-textured soils. Geoderma 187-188:59-66.

Wang Z., Feyen, J., van Genuchten M.Th., Nielsen D.R. 1998. Air entrapment effects on infiltration rate and flow instability. Water Resour. Res. 34:213-22. 